\title{
How to optimize learning Observational learning from animated models: A review of guidelines based on cognitive load.
}

Citation for published version (APA):

Wouters, P., Paas, F., \& Van Merriënboer, J. (2008). How to optimize learning Observational learning from animated models: A review of guidelines based on cognitive load. Review of Educational Research, 78(3), 645675. https://doi.org/10.3102/0034654308320320

DOI:

$10.3102 / 0034654308320320$

Document status and date:

Published: 01/09/2008

Document Version:

Peer reviewed version

Please check the document version of this publication:

- A submitted manuscript is the version of the article upon submission and before peer-review. There can be important differences between the submitted version and the official published version of record. People interested in the research are advised to contact the author for the final version of the publication, or visit the DOI to the publisher's website.

- The final author version and the galley proof are versions of the publication after peer review.

- The final published version features the final layout of the paper including the volume, issue and page numbers.

Link to publication

\section{General rights}

Copyright and moral rights for the publications made accessible in the public portal are retained by the authors and/or other copyright owners and it is a condition of accessing publications that users recognise and abide by the legal requirements associated with these rights.

- Users may download and print one copy of any publication from the public portal for the purpose of private study or research.

- You may not further distribute the material or use it for any profit-making activity or commercial gain

- You may freely distribute the URL identifying the publication in the public portal.

If the publication is distributed under the terms of Article $25 \mathrm{fa}$ of the Dutch Copyright Act, indicated by the "Taverne" license above, please follow below link for the End User Agreement:

https://www.ou.nl/taverne-agreement

Take down policy

If you believe that this document breaches copyright please contact us at:

pure-support@ou.nl

providing details and we will investigate your claim.

Downloaded from https://research.ou.nl/ on date: 26 Apr. 2023 


\title{
Running head: DESIGN GUIDELINES FOR ANIMATED MODELS
}

This is a pre-print of the article that was published as Wouters, P.J.M., Paas, F. \& van Merriënboer, J. J. G. (2008). How to optimize learning from animated models: A review of guidelines based on cognitive load. Review of Educational Research, 78, 645-675

How to Optimize Learning from Animated Models? A Review of Guidelines based on

Cognitive Load

\author{
Pieter Wouters* ${ }^{1}$, Fred Paas ${ }^{2,3}$, and Jeroen J. G. van Merriënboer ${ }^{2}$ \\ ${ }^{1}$ Institute of Information and Computing Sciences \\ Utrecht University, the Netherlands \\ ${ }^{2}$ Educational Technology Expertise Centre, \\ Open University of the Netherlands, Heerlen, the Netherlands \\ ${ }^{3}$ Institute of Psychology, \\ Erasmus University Rotterdam, the Netherlands
}

Key words: cognitive load theory, cognitive modeling, animations

Correspondence concerning this article should be addressed to Pieter Wouters, Utrecht

University, Institute of Information and Computing Sciences, P.O. Box 80.089, 3508 TB

Utrecht, the Netherlands. E-mail: mailto: p.j.m.wouters@ cs.uu.nl, Tel. +31 302539219

Author Note

This research project is funded by the Netherlands Organization for Scientific Research

NWO, The Hague, project number: 411-02-163) 


\begin{abstract}
Animated models explicate the procedure to reach a problem solution as well as the rationale behind this procedure. For abstract cognitive processes, animations might be beneficial especially when explanations are provided by a supportive pedagogical agent. We argue that animated models can be an effective instructional method provided that they are designed in such a way that cognitive capacity is optimally employed. This review proposes three sets of design guidelines based on cognitive load research. The first set aims at managing the complexity of subject matter. The second set focuses on preventing activities -due to poor design- that obstruct learning. The last set of guidelines incites learners to engage in active and relevant processing of subject matter. Finally, an integrative framework is presented for designing effective animated models.
\end{abstract}


How to Optimize Learning from Animated Models? A Review of Guidelines based on Cognitive Load

The current focus on lifelong learning and flexibility in task performance increasingly emphasizes the mastering of complex cognitive skills (Jonassen, 1999). Instructional methods, such as modeling and vicarious learning, in which learners observe how experts perform problem-solving tasks and simultaneously explain the reasoning underlying their actions, fit this focus on complex learning. At the same time, rapid developments in computer and software technology in the last decades have enabled the use of animations to illustrate abstract cognitive processes or concepts (Casey, 1996; Chee, 1995; Collins, 1991) and programmable pedagogical agents to support learners.

We refer to the combined use of animations and pedagogical agents in modeling as animated models. These animated models illustrate the solving of problems such as scientific problems (e.g., solving a problem about gravity), mathematical problems (e.g., probability calculation problems), or search problems (finding information on the Internet). The pedagogical agent functions as a social model and guides the learner through the animation, for example, by moving around the screen and guiding the learner's attention to specific parts of the animation, by addressing the learner in a personalized style and/or by showing which errors typically may occur and how they may be avoided by the learner. For example, in solving a problem in the domain of probability calculation, it is important to know whether it is a 'drawing with or without replacement'. For novices this concept may be rather abstract and difficult to understand. An animation can visualize the concept by showing what is happening in, for instance, a situation in which the probability has to be calculated that a 
person guesses the correct pin code of a cash card in one trial. As depicted in Figure 1a, the animated model may show someone standing before an ATM machine. For the first number of the pin code, this person may choose from the ten figures located right from the ATM display.

\section{Insert Figure 1a here}

For the second number of the pin code, the person again may choose from ten figures. This is shown in Figure $1 \mathrm{~b}$ in which the pedagogical agent guides the attention to the ten figures that have become highlighted and explain that the figure that is used for the first number of the pin code can also be used for the second number.

\section{Insert Figure $1 b$ here}

This illustrative animated process and its explanation by the pedagogical agent continues until the problem is solved.

A potential danger of showing the performance of a complex task with visualizations and verbal explanations is that the limited cognitive capacity of learners might become overloaded. Cognitive load theory emphasizes this limitation as an important determinant for the effective use of instructional methods (Paas, Renkl, Sweller, 2003, 2004; Sweller, 1988, 1999, 2004; Sweller, van Merriënboer, \& Paas, 1998; van Merriënboer \& Sweller, 2005). In this paper we argue that animated models can be an effective instructional method, provided that they are designed in such a way that cognitive capacity is optimally employed. We will propose a set of design guidelines to accomplish this. For this purpose we selected design guidelines from review publications of leading researchers in the field (e.g., Mayer, 2001, 2005a, 2005b, 2005c; Moreno, 2005; Mayer \& Moreno, 2002, 2003; Sweller, 1999, 2005, 2006; Sweller et al, 1998; van Merriënboer \& Sweller, 2005). We also conducted a literature search with these design guidelines as search terms in the PsycINFO and EJS E-journals 
databases. Additionally, we also searched in these databases with broader descriptors, such as, 'cognitive load', 'animations', ‘dynamic visualizations', and 'multimedia'. In cases that too much output was generated we further limited the search results with terms, such as, 'learning', 'instruction', and 'training'. Finally, the resulting scholarly output was then narrowed by selecting studies that were applicable to animated models.

In this paper we will first give an outline of cognitive load theory. Second, we will further elaborate on the nature of animated models, that is, attention will be paid to cognitive modeling, animations, and pedagogical agents. Third, design guidelines are proposed that enable learners to engage in more effective learning from animated models. The last section draws some conclusions and provides directions for further research.

\section{Cognitive Load Theory}

Cognitive load theory tries to align the structure of information and the way it is presented with human cognitive architecture. In order for learning to commence, people have to process information and the degree in which the complexity of information varies is a qualifying factor. For the processing of information two structures in human cognitive architecture are crucial. Working memory, where all conscious processing of information takes place, only has a limited processing capacity that is by far inadequate to meet the complexity of information learners face in modern learning environments. The second structure, long-term memory, is a knowledge base with a virtually unlimited capacity that can serve as added processing capacity by means of schemas. Schemas comprise cognitive structures in which separate information-elements are aggregated in one specialized element that can be processed by working memory as a single element (Paas et al., 2003). For example, in a complex skill like driving a car, less experienced drivers need to bring the separate elements, such as declutching, shifting the gear and engaging the clutch, one by one 
into working memory in order to successfully change gears. More experienced drivers, on the other hand, have aggregated these separate elements in one 'changing gear' schema that can be processed by working memory as one element. The acquisition and automation of such schemas- so that they can be processed unconsciously- is important because it further optimizes the processing capacity of working memory.

From the perspective of instructional design, information can impose a cognitive load in three ways. First of all there is cognitive load that depends on the element interactivity of the subject matter; complex information consists of a multitude of elements that interact with each other. One can only speak of 'understanding' such complex information when the separate elements are processed as well as the way they interact (Chandler \& Sweller, 1994, 1996). For instance, in acquiring a foreign language, learning word pairs is associated with less element interactivity than understanding the grammar of a sentence. For learning word pairs, only two elements need to be active in working memory. However, for understanding a sentence, the words in the sentence have to be held in working memory as well as the grammatical relationships between these words. For example, in order to understand that a sentence like 'Two children are sitting on a couch' is correct, but that 'Two children is sitting on a couch' is not, the learner has to hold the separate words in working memory but also the grammatical parts like subject and verb and their relation (i.e., the plural of the subjects has a consequence for the conjugation of the verb). In cognitive load theory this is called intrinsic cognitive load and it can be regarded as a necessary base load, because it cannot be reduced without compromising full understanding. The more complex a skill, the higher the intrinsic cognitive load because of higher element interactivity.

Second, the way that information is presented can also impose a cognitive load. Extraneous or ineffective cognitive load is imposed on working memory because of poorly 
designed instructional material. Sometimes, learners have to engage in cognitive activities that do not directly contribute to learning but that are used to overcome the deficiencies of the design. One of the most investigated phenomena with respect to extraneous cognitive load is the split-attention effect (Kalyuga, Chandler, \& Sweller, 1999; Mayer \& Moreno, 1998; Tarmizi \& Sweller, 1988), which occurs when two (or more) sources of information must be processed simultaneously in order to derive meaning from subject matter. Take for example the situation of a diagram about assembling a machine for which explanatory text is presented on another page. The learner has to mentally search, match and integrate both sources of information, which imposes a high extraneous cognitive load on working memory. This high load might interfere with learning.

Third, germane or effective cognitive load is imposed when information is presented in such a way that learning is enhanced, that is, when it facilitates the construction and/or automation of cognitive schemas. The assumption is that active processing will yield germane cognitive load. In this respect, the generation of self-explanations has proven to be an effective cognitive activity that enhances learning (Chi, Bassok, Lewis, Reimann, \& Glaser, 1989; Renkl, 1997; Renkl \& Atkinson, 2002). Take for example an expert who has shown how to solve a problem in probability calculation. Novices might engage in relevant learning activities when they are incited to explain the observed problem-solving process and the resulting problem solution to themselves, and in this way acquire or refine their cognitive schemas.

The three types of cognitive load are not isolated but act as additive components. The combined load of these components cannot exceed the available cognitive capacity and, consequently, the high load of one component is at the cost of another component. When intrinsic cognitive load is high it becomes important to decrease extraneous cognitive load, 
otherwise the combination of both might exceed the maximum cognitive capacity and thus prevent effective or germane activities to occur. From an instructional design point of view, especially extraneous cognitive load and germane cognitive load should be considered as communicating vessels as the reduction of extraneous cognitive load can free cognitive resources for an increase in germane cognitive load (Paas et al., 2003).

\section{Modeling}

The modeling and the vicarious learning literature emphasize that learning by observing experts (or advanced novices) who display their performance of physical and/or cognitive skills can enhance learning (Bandura, 1976, Collins, Brown, \& Newman, 1989; Cox, McKendree, Tobin, Lee, Mayes, 1999; van Merriënboer, 1997). Two arguments support this assertion. First, when observing an expert performing a complex task in which both knowledge and skills are integrated, the learner can construct an adequate cognitive representation. This representation guides appropriate performance and enables the learner to mentally (or physically) rehearse the task, which in turn refines the initial representation. Second, compared with other instructional methods like worked-out solutions, learning by observation of a model might be beneficial, because it not only shows what is happening, but also why this is happening (Collins, 1991; van Gog, Paas, \& van Merriënboer, 2004).

Problem solving, for example, can be regarded as the application of several steps in order to solve the problem, but this approach does not take into account why some steps are chosen and others are not, to solve the problem. In this way more generalized schemas might be constructed that can be applied in a variety of contexts or problem formats. Moreover, the expert might tell about false starts and dead ends and enable the observer to learn what kind of response to avoid without the need of making the error themselves (Bandura, 1976; Cox et al., 1999). 
According to Collins et al. (1989), expert performance can be divided in the performance of physical skills and processes and the performance of cognitive skills and processes. On the one hand, learning the appropriate muscle movements for learning to write, to ski, to play tennis or to throw darts typically involves behavioral modeling, that is, the expert shows the desired physical performance (Kitsantas, Zimmerman, \& Cleary, 2000; Zimmerman \& Kitsantas, 2002, see for a review, Wetzel, Radtke, \& Stern, 1994). Modeling of cognitive skills and processes, on the other hand, requires the explication of considerations, thoughts and reasons that underlie the performance of actions or choices. Problem solving (Jonassen, 1999) and cognitive behavior modification (Meichenbaum, 1977) are examples of domains that essentially involve cognitive modeling.

It is a problem, regarding skills and processes in the cognitive domain, that they are not readily observable. When a novice observes an expert solving a problem, all the thoughts, considerations, and reasons might be traced back or concluded from the results, but the observer cannot actually perceive the cognitive performance. To overcome this problem, the cognitive skills and processes of the expert that occur internally have to be externalized. In their description of cognitive apprenticeship learning, Collins et al. (1989) discuss some approaches in which the externalization of cognitive skills is practiced by having teachers, the models, speak out aloud their considerations with respect to heuristics (e.g., rules of thumb) and control processes in fields like writing and mathematics.

When abstract concepts or processes are involved that have no physical counterpart, cognitive modeling might become difficult. For example, in debugging, which is an important aspect of learning computer programming, a novice programmer tries to find out what happens when an error occurs in the program code. Cognitive modeling could be used to show how an expert programmer finds out what specific cause-and-effect relations exist in 
the program code and which reasoning underlies these considerations. However, it is difficult to externalize the expert's considerations about concepts such as readability, robustness, and processes such as inheritance of properties in such a way that it helps learners to construct a mental representation. In this respect, the use of dynamic visualizations such as animations might be helpful to illustrate these concepts and processes.

\section{Animations}

One of the most comprehensive theories about multimedia learning is Mayer's cognitive theory of multimedia learning (Mayer, 2001, Mayer \& Moreno, 2003). This theory can be considered a further extension of dual coding theory from which it adopts the dual channel assumption. This assumption implies that information is processed in two separate channels: A verbal system, which basically comprises written language and spoken language, and a nonverbal system, which processes pictorial materials (Clark \& Paivio, 1991, Paivio, 1986). A fundamental prediction of dual coding theory is that both systems are additive and that people learn better when the presented information is encoded both verbally and visually rather than in one system only. Information that has been encoded in two ways can be retrieved from memory more easily. Whereas the vast majority of dual coding theory research has been conducted with static visualizations, the cognitive theory of multimedia learning has focused on dynamic visualizations. Probably the most widespread type of a dynamic visualization is the animation that can be regarded as the presentation of frames in such a way that each frame appears as an alteration of the previous one, with a speed that creates the illusion of apparent motion (Rieber \& Kini, 1991). Often, the animation is combined with explanatory verbal information. The cognitive theory of multimedia learning argues that different mental representations have to be constructed from verbal and pictorial information, but simultaneously these representations have to be actively integrated in order for 
meaningful learning to commence (Mayer, 2001; Mayer \& Moreno, 2003; Mayer \& Sims, 1994).

Four characteristics of animations can be found that are relevant for (cognitive) modeling. The first characteristic is that animations can present information that changes with time, such as the working of a device or the explanation of a procedure by movement of objects in the animation (Ainsworth \& VanLabeke, 2004; Hegarty, 2004, Tversky, Morrison, \& Betrancourt, 2002; Rieber, 1990; Weiss, Knowlton, \& Morrison, 2002). Although the movement of objects is an important type of change within an animation, yet other types of changes can be distinguished. An interesting division is made by Lowe (1999, 2003), who conceives animations as consisting of one or more objects that may undergo several types of changes. First of all there are transformations that can be regarded as changes in properties of objects like color, shape, and size. Subsequently there are translations, which refer to movements of objects on the screen. Finally there are transitions that concern the appearance and/or disappearance of objects. These three types of changes can occur in an isolated fashion (e.g., an object starts flashing), but will typically occur together (e.g., an object starts flashing and moving). In complex animations, more objects exist and each object can have its own regime of changes. For example, in a meteorological animation several high-pressure and low-pressure areas may exist that move into several directions (i.e., translations), expand or shrink (i.e., transformations), and arise or disintegrate (i.e., transitions). From a cognitive load perspective, the dispersion of information in parts that follow each other sequentially or that are presented simultaneously might be problematic: Once a part of the information is missed or only partly processed, the remaining parts might become incomprehensible. In order to build a coherent representation, the learner has to hold and integrate information from these different parts in working memory and then store it in long-term memory (LTM), otherwise 
they will not be able to retrieve the information in that part. If the following part of the animation has to be processed before the earlier part is stored in LTM, this new information will interfere with remembering the information in the earlier part. This phenomenon is called retroactive inhibition (Baddeley, 1997) and may be reinforced by the fact that people have limited time to study each part of an animation because of its transient nature (Lowe, 1999, 2003). In the case of poor design of the animation, that is, when extraneous cognitive load is involved, retroactive inhibition due to limited processing time uses up cognitive resources that could better be used for building the cognitive representation.

A second characteristic of animations is that they can be seen as depictive external representations (Schnotz, 2002). The depictive nature of animations enables the visualization of concrete concepts, such as the working of a bicycle pump that can be depicted by the animation of its working, or of abstract concepts that are represented by concrete events, such as the term 'drawing without replacement' in probability calculation that can be depicted by drawing marbles from a vase without returning them. Moreover, an advantage of animations is that they can be shaped, distorted, or manipulated by showing an object, for example, from multiple perspectives or by making it larger or smaller (Hegarty, 2004; Schwan \& Riempp, 2004).

The third characteristic is that the animation's salient features, such as motion and flashing, can focus the learner's attention to relevant parts of the screen (Park \& Hopkins, 1993; Wetzel et al., 1994). This can be relevant for novices who might be overwhelmed by complex animations (Rieber, 1990). In the animation of a complex system, for example, a flashing arrow could highlight the critical features of the system.

A fourth characteristic reported by a number of researchers is that animations can motivate learners by their cosmetic appeal (Shah \& Freedman, 2003; Weiss et al., 2002). For 
example, animated agents can be used to reduce potentially upsetting information and popular cartoon figures can be used to engage young learners in learning (Wetzel et al., 1994).

These four characteristics make animations potentially useful in conjunction with cognitive modeling. Take, for example, an animation in which an expert is telling how meteorological data have to be interpreted in order to give a sound weather report. The expert verbalizes that several low-pressure and high-pressure areas exist, how they interact with each other and how they are geographically related to each other. An animation could visualize this situation and make it easier for a novice observer to make a mental representation of it. Moreover, when the expert is stressing the importance of a low-pressure area that is shrinking, the animation could focus the learner's attention on this by zooming in on the particular area.

Although dynamic visualizations seem very appealing, several studies and reviews have shown that the dynamic visualizations are -at best- not more effective and occasionally even less effective than static visualizations. In an extensive review, Tversky et al. (2002) reported that in general dynamic visualizations were not more effective than static visualizations. In the cases that they were more effective this could be ascribed to more detailed information that was available in the dynamic visualizations or because of the benefits from study procedures, such as prediction, that were not available in the static visualizations. In the domain of mechanical systems, Hegarty, Kriz, and Cate (2003) compared learning from animated graphics with static diagrams and concluded that both types of visualizations resulted in better learning but that the animated graphics did not lead to superior performance. In other cases it was found that the use of dynamic visualizations led to more time spent on instruction without corresponding gains in learning outcomes 
(Koroghlanian \& Klein, 2004). These studies make clear that there is no strong evidence to ground any claim that dynamic visualizations are better than static visualizations. In their analysis, Tversky et al (2002) formulated two principles that specify the conditions under which dynamic visualizations may be effective, although not necessarily more effective than static visualizations. First, they postulate the apprehension principle, stating that the structure and content of a dynamic visualization should be readily perceivable and comprehensible (e.g., a dynamic visualization should not go too fast). Second, the congruence principle explains that the structure of a dynamic visualization should correspond with the way people conceive the processes or procedures that are visualized. For example, if operating a machine is conceived as a sequence of discrete steps, a dynamic visualization should visualize it that way.

We concur with the notion that we should focus on identifying the conditions under which dynamic visualizations might indeed promote learning (Hegarty, 2004; Mayer \& Moreno, 2002; Tversky et al, 2002). Furthermore, we contend that dynamic visualizations might become more effective when they are designed in such a way that cognitive capacity is optimally employed. In this respect, a series of four experiments conducted by Mayer, Hegarty, Mayer, and Campbell (2005) is of interest. Overall, the results of these experiments showed that dynamic visualizations (narrated animations) resulted in poorer learning than static visualizations (illustrations on paper). Although Mayer et al. explained these findings in terms of the cognitive theory of multimedia learning, we contend that the dynamic visualizations in these experiments were not designed in such a way that learners' cognitive capacity was optimally employed. We concur with the authors' conclusion that the static visualizations were learner-paced and segmented in meaningful units, whereas the dynamic visualizations were computer-paced and continuous. But as we will argue later, we consider 
both learner-pacing and segmentation as design guidelines that can also be used in combination with dynamic visualizations in order to decrease extraneous cognitive load and thus release cognitive capacity for genuine learning.

\section{Animated Pedagogical Agents}

Cognitive modeling involves complex skills that often have to be applied in specific contexts in which a problem has to be examined from several perspectives. For novices this can pose a problem and support given by a pedagogical agent (e.g., a tutor, a peer student, a software agent) might be helpful. Animated pedagogical agents are computerized characters that appear on the screen and support the learner, which include guiding, coaching, and providing feedback, as they engage in a task by verbal (e.g., explanations) as well as nonverbal communication, such as, gazing and gesturing (Atkinson, 2002; Clarebout, Elen, Johnson, \& Shaw, 2002; Moreno, 2005). These animated pedagogical agents can be humanlike (e.g., "Herman the Bug", an insect with some facial expression used in several research projects) or not (e.g., the well-known "Paperclip" of Microsoft Office).

The last five years several reviews and studies concerning the instructional value of animated pedagogical agents have been published. An instructional advantage put forward by researchers is the potential of animated pedagogical agents to motivate learners (Dehn \& van Mulken, 2000; Moreno, Mayer, Spires, \& Hiller, 2001; Moundridou \& Virvou, 2002). For example, Moreno et al. (2001) found that learners in a learning environment with an animated pedagogical agent were more motivated and interested. Moreno and colleagues explained this motivation effect with the social agency theory that assumes that learners in a social-agent learning environment tend to work harder. Social agency theory was derived from the media equation hypothesis (Reeves \& Nass, 1996), which claims that people view interaction with media, such as computers and software, as interaction with humans and that therefore social 
rules that apply for human-to-human interaction also apply for human-media interaction. According to social agency theory, multimedia instruction can be regarded as information delivery or as a social event. When social cues are incorporated in the multimedia instruction, people will interpret the interaction with the computer as a social event. The theory further argues that these social cues will prime social conversation and so engage the learner in efforts to make sense of what the multimedia instruction is saying (Moreno et al., 2001). Furthermore, Moundridou and Virvou (2002) found that an animated pedagogical agent made learning in a learning environment with algebraic word problems easier and more pleasant in the perception of the learners.

Another didactical function, which is enabled by the current state of technology, is that animated pedagogical agents can be programmed to adapt to the characteristics of a specific learner or to the context in which a task is performed (Clarebout et al., 2002, Clark \& Choi, 2005). For example, the agent could scaffold the amount of support and guidance that is provided, by performing parts of the task that learners cannot perform on their own, by coaching, and by providing hints and feedback specific for a learner.

Reviews regarding the benefits of animated pedagogical agents report mixed results: In some empirical studies animated pedagogical agents yield better learning (e.g., Moreno et al., 2001), whereas other studies did not find these learning benefits (Clark \& Choi, 2005; Dehn \& van Mulken, 2000). We contend that animated pedagogical agents must be applied carefully. To start with, it seems that the effect of these agents is domain-specific. For example, in their review Dehn and van Mulken (2000) concluded that the effect of an anthropomorphized agent on entertainment value is domain-specific. In a technical system an anthropomorphized animated pedagogical agent was more entertaining than an agent with a geometrical interface, whereas in a system for introducing new employees in an organization 
no difference in entertainment value was found. The same pattern was found for assessed task difficulty: When technical information was presented, lower task difficulty was reported when the information was referred to by an animated agent than when it was referred to by a pointing arrow. Again, for the introduction of new employees no difference in perceived task difficulty was found between the animated agent and the pointing arrow.

A second comment pertains to the preference of learners for animated pedagogical agents. Craig, Grasser, Sullies, and Gholson (2004), for example, investigated the relation between different types of affect, such as boredom, flow and confusion and learning in a learning environment about computer literacy which included an animated conversational agent which was capable of synthesized speech, gestures, and facial expressions. While learners worked in the learning environment, their emotions were tracked and coded. It was found that affects like confusion and flow correlated positively with learning gains, whereas an affect like boredom correlated negatively with learning gains. Trying to ignore an animated pedagogical agent that doesn't motivate learners, but bores or even annoys them, imposes an ineffective cognitive load (i.e., extraneous load).

To conclude, we contend that the processing of a sophisticated animated pedagogical agent with many salient details might require so much cognitive capacity that little remains for processing the actual subject matter. We believe that animated pedagogical agents can be beneficial when they are designed according to the guidelines provided by cognitive load theory.

\section{Design Guidelines for Animated Models}

The purpose of the remainder of this article is to propose guidelines for decreasing extraneous and, if necessary, intrinsic cognitive load as well as for increasing germane cognitive load. First, some guidelines will be discussed to decrease intrinsic cognitive load. 
Guidelines that primarily aim at reducing or managing the element interactivity of subject matter are classified under this category. Second, when guidelines reduce activities that obstruct learning (e.g., visual search caused by split-attention effects) they are listed as guidelines to decrease extraneous cognitive load. These guidelines may help to free up processing resources that can subsequently be devoted to learning. Finally, design guidelines are presented to increase germane cognitive load. These guidelines may help to make good use of the cognitive resources that have become available through decreasing intrinsic and/or extraneous cognitive load. The criterion for these guidelines is that they should prompt learners to engage in active processing of subject matter. It should be noted that some guidelines may have an effect on more than one type of cognitive load. For example, element interactivity may be reduced by providing a simple animated model. It is obvious that such a simple animated model may also involve less visual search and thus cause less extraneous cognitive load. In these cases the guideline will be classified under the category it primarily aims at. In addition to this, guidelines may be categorized differently in other classifications. For example, Mayer (2005a) regards segmentation as a guideline for decreasing intrinsic cognitive load, whereas in this review it is assumed to decreases extraneous cognitive load. In these cases we briefly discuss these differences.

For each guideline an example will be provided. For the sake of clarity we will apply each guideline to the 'pin code' animated model which was already described in the introduction. In this animated model a person has to guess the correct pin code in one trial. In the animated model a pedagogical agent explains the steps that are needed to calculate the probability that this person guesses the correct pin code. 
The first guideline to decrease intrinsic cognitive load focuses on scaffolding learners when they perform so-called whole tasks. In whole tasks, learners have to coordinate and integrate different skills and knowledge so that they develop a holistic view on the nature of the task (van Merriënboer, 1997). However, for novices complex whole tasks may be overwhelming and impose a high level of intrinsic cognitive load. Therefore, a sequence of simple-to-complex whole tasks is proposed starting with relatively simple whole tasks that enable learners to construct and automate schemas before they commence with more complex whole tasks (van Merriënboer, Kirschner, \& Kester, 2003; van Merriënboer \& Sweller, 2005). A complex skill like "searching for literature", for example, can be simplified by defining conditions that will make a task more simple without compromising its whole task nature, such as the clearness of the concepts used, the number of the articles in the domain, the number of databases that will be searched for relevant literature, the type of search, and the number of search terms. The simplest whole task that learners are initially confronted with pertains to a domain with clearly defined concepts, in which search terms on keywords that are not interconnected by 'and' or 'or' operators results in a limited number of articles, originating from only one database. Whole tasks with increasing complexity can be constructed by variations in these conditions, for example, learners have to conduct a search in several databases with many search terms that have to be connected with 'and' and 'or' operators (van Merriënboer et al., 2003).

With respect to the 'pin code' animated model an additional animated model with more complex conditions can be provided. One of the conditions that determine the complexity of probability calculation is the number of individual events that have to be considered. In the original 'pin code' animated model four of such events had to be taken into account, that is, the four numbers of the pin code. Then, the additional animated model could 
be made more complex by increasing the number of individual events, for example, by having to calculate the probability that someone correctly guesses a pin code consisting of six numbers.

A second guideline releases the whole-task approach and can be characterized as pretraining, because it departs from the view that first isolated components have to be instructed before learners are exposed to the interaction of these components (Mayer, 2005a; Mayer \& Moreno, 2003). For example, in meteorology learners first are instructed what highpressure and low-pressure systems are before they learn how these systems interact with each other and determine the weather in a region. Pollock, Chandler, and Sweller (2002, Experiments 1 and 3) reduced the complexity in the domain of testing electrical safety by presenting part of the subject matter in a pretraining. In the first phase only the isolated components were presented to enable novices to construct a schema of these components. In the second phase all informational components as well as the interactions between them were explained. It should be noted that the kind of reduction in the first phase may lead to an initial decrease in the learner's understanding, which is compensated for by an increase in understanding in the second phase. Pollock et al. found that a group of novices exposed to a similar two-phase instruction outperformed a group that was exposed twice to an interactingcomponents -only instruction (there was no difference in instruction time). Similar results were found by Mayer, Mathias, and Wetzell (2002) with learning how brakes and pumps work. Learners performed better on transfer when they first received a short training about the names and behaviors of the components, followed by a narrated animation about the way these components interacted. Finally, in a cause-and-effect system (origin of lightning), Mayer and Chandler (2001, Experiment 1) first had novices learn the isolated components, which enabled them to build a rudimentary schema, followed by an instructional phase in 
which they learned about the causal relation between these components. It was found that learners who followed this treatment scored better on transfer than learners who received either twice an instructional format in which the components and their causal relations were integrated, or a group who received first instruction about the causal relations between the components followed by instruction of the components only. A problem with this study was that instruction time was not recorded and that it can not be concluded definitely that the experimental treatment caused the effect or a prolonged instruction time.

In probability calculation problems, such as the one used in the 'pin code' animated model, the solution method depends on the interaction between 'drawing with replacement or not' and 'order relevant or not'. Then, in a pretraining strategy first definitions of concepts like 'drawing with replacement or not' and 'order relevant or not' as well as relevant formulas are instructed. After that the 'pin code' animated model can be studied in which it is shown how 'drawing with replacement or not' and 'order relevant or not' interact and determine which method can be used to solve this problem.

In conclusion, pretraining seems more appropriate for animated models in which causal relations prevail, such as, cause-and-effect systems or the working of devices, but less appropriate for animated models in which procedures are involved. Consequently, pretraining seems less suitable to apply in the 'pin code' animated model.

\section{Guidelines for Decreasing Extraneous Cognitive Load}

The first guideline, pacing, involves the control over the continuation of the presentation of instructional material, which can be exerted by either the learner or the system (e.g., a computer). Learner pacing might enable learners to adapt the presentation of instructional material to their cognitive needs (e.g., by pausing the instruction or going backward in the material). Schwan and Riempp (2004) showed in a study with a video about 
nautical knotting that pacing (instantiated by accelerating, decelerating, stopping or repeating the video) was heavily used, especially with increasing knot difficulty. The more difficult the knots became, the more pacing was used, which resulted in a better understanding of the underlying processes, that is, less practice time was needed to reproduce the knots correctly. Other studies (Mayer \& Chandler, Experiment 2, 2001; Mayer, Dow, \& Mayer, Experiment $2 a$ and $2 b, 2003$ ) reported a learner pacing effect, but the effect of either instruction time on transfer performance or the segmentation of instructional material was not taken into account. It is not clear whether the positive effects can be ascribed to learner-pacing, the prolonged instruction time, or the segmentation of instructional material.

On the other hand, there are studies in which pacing was a manipulated factor that report mixed results. Recently, Moreno and Valdez (2005, Experiment 2) failed to find a learning advantage on transfer for learner pacing compared with system pacing. The learnerpaced group even took less time than the system-paced group, which seems to suggest that learners in the former condition might not have been motivated enough to work through the learning environment. Tabbers, Martens and van Merriënboer (2004) further qualified the pacing effect as they found that with learner pacing, learners who received written explanations outperformed learners who received spoken explanations on transfer test performance. Possibly, the absence of time pressure for learner pacing enabled learners to process the written text strategically (i.e., scan the text, reread).

In the 'pin code' animated model, a limited version of learner pacing, may enable learners to pause and continue the animated model. In a more sophisticated version of learner pacing, learners might also move forward or backward in the animated model (e.g., with a slider bar they can go quickly forward by dragging the slider to the right). 
To conclude, the findings seem to suggest that considerations regarding pacing, such as when to apply pacing, might interrupt the processing of information and thus impose such an extraneous load on the cognitive system of novices that little resources remain for learning. Possibly, pacing should be implemented in conjunction with other guidelines, such as segmentation.

A second guideline is to apply segmentation. The segmentation of an event can be based on the model of event perception (Zacks \& Tversky, 2001), which assumes that a continuous event is cognitively represented in a highly structured manner. According to the model of event perception, events can be decomposed into segments that subsequently consist of activity steps. Zacks and Tversky provided evidence that activity steps with high informative value correctly characterized the segment of which they were part, whereas activity steps with low informative value failed to represent that segment. The places in the event where these highly-informative activity steps occur are regarded as 'breakpoints.' With respect to learning procedural tasks (e.g., upgrading a computer) from videos, Schwan and Garsoffky (2004) found evidence that these breakpoints are important: They observed that summaries of procedural tasks based on breakpoints were perceived as equally comprehensible as the complete video, but as more comprehensible than summaries based on non-breakpoints.

Moreover, they found that the omission of breakpoints resulted in higher cognitive costs because the event structure was lost and participants had to use their cognitive resources to cope with this break in the coherence of the event. This observation is in line with Schwan, Garsoffky, and Hesse (2000), who argued that film-cuts on places where breakpoints occur can facilitate the cognitive processing of breakpoints as they make these more salient. Because less effort is needed to search for breakpoints, more cognitive resources are available 
for building a cognitive representation. Furthermore, in a cause-and-effect system (origin of lightning), Mayer and Chandler (2001, Experiment 2) reported that learners who received an animation that was divided into a set of segments scored better on transfer than learners who received a continuous animation. It should be noted, however, that segmentation is only effective when the learner has completed the processing of one particular segment before the next segment is presented.

In the 'pin code' animated model, the problem solving process can be regarded as an event. Each segment could correspond with one important step in the problem solving process. For example, in segment 1 it is determined whether it is a 'drawing with replacement or not'; segment 2 determines whether the 'order is relevant or not'; based on this information the problem solving method is chosen in segment 3 ; in segment 4 the problem solving method is applied, and finally, in segment 5 the probability is calculated.

A final remark concerns the fact that other perspectives exist on the classification of the segmentation guideline. Whereas in this review segmentation is regarded as a technique that may help learners to prevent visual search, there is also the point of view that regards segmentation as a technique for decreasing intrinsic load (Mayer, 2005a, Mayer \& Moreno, 2003). In the present review, segmentation is considered in isolation, contrary to the other classification in which segmentation is applied in conjunction with pacing. We agree that segmentation in combination with learner pacing may help learners to overcome the complexity of subject matter and in that respect decrease intrinsic cognitive load.

The third design guideline is the application of the modality principle. Modality refers to the sensory mode in which verbal code is presented, either in a written or spoken format (Penney, 1989). Research with respect to the modality of presentation has indicated that spoken verbal explanations are generally superior to written explanations, when used in 
combination with pictorial learning material (Mayer, 2005a; Moreno \& Mayer, 1999; Mousavi, Low, \& Sweller, 1995; Sweller et al., 1998; see for a meta-analysis: Ginns, 2005). This is ascribed to the modality principle: The combined use of the visual channel for pictorial learning material and the verbal channel for the explanation of this material increases effective working memory capacity and so facilitates learning. More recently the modality principle was further qualified. To start with, Tabbers (2002) found that pacing was an important factor as written explanatory text was more effective than spoken explanatory text when learners had control over the pacing of the presentation. Possibly, the absence of time pressure for learner-controlled pacing offers the possibility to process the written text strategically. Secondly, Mayer, Sobko, and Mautone (2003) observed that learners who heard a spoken explanation in a standard accent performed better on transfer than learners who heard the same explanation with a foreign accent (Experiment 1). Similarly, they found that a human voice resulted in better transfer than a synthesized voice (Experiment 2). Spoken explanations can be used if the 'pin code' animated model requires so much visual search that little cognitive capacity remains for processing writing explanations.

It should be noted that Mayer (2001, 2005a; Mayer \& Moreno, 2003) considers the modality principle as a guideline to decrease intrinsic cognitive load. In this review we regard the modality principle primarily as a guideline to overcome the split-attention effects, typical for complex animated models, and so decrease extraneous load. However, we concur with Mayer that using spoken explanations instead of written explanations implies that more information can be processed through the visual channel. In this way more cognitive capacity becomes available for processing complex subject matter.

The fourth guideline pertains to the use of the contiguity principle. The contiguity principle states that verbal explanations accompanying pictorial material should be presented 
contiguously in time or space to overcome the split-attention effect. The rationale underlying the spatial contiguity principle is that visual search between for example, written explanations and pictorial information is reduced so that cognitive capacity is released for relevant learning activities (Mayer, 2005b). For temporal contiguity, the rationale is that both the explanation and the pictorial information are simultaneously held active in working memory which is a condition for integrating both information sources (Mayer, 2005b). In an animation about the formation of lightning, Mayer and Moreno (1999, Experiment 1) observed that learners who received written explanatory text that was close to the animation performed better on transfer than those who received text that was physically far away from the animation. Mayer and Sims (1994) compared concurrently and successively delivered spoken explanatory text that accompanied an animation. Learners who received the concurrent narrated animation performed better on transfer than learners who received the successive narrated animation. This result was confirmed by Mayer, Moreno, Boire, and Vagge (1999). The latter study also revealed that the temporal contiguity effect was eliminated when the successive narration was broken up in small parts that lasted only a few seconds. Apparently, the fast alternation between narration and animation enables the learners to make connections between the verbal and pictorial information without overloading the cognitive system.

When the expert points to the highlighted ten figures in the 'pin code' animated model from which the person can choose the second number of the pin code, the explanation that the person can choose one of these ten figures must be spoken at the same time or, when written, the text should appear very close to the highlighted figures.

The fifth and last guideline is the application of signaling or cueing. According to Mayer and Moreno (2003) signaling is the provision of cues to the learner how to select and 
organize the instructional material (see also Mayer, 2005b). In this respect signaling covers a broad spectrum including stressing key words in a speech, organizing words in printed text by underlining them, and presenting images such as arrows to focus the attention to a particular part of an animation. This review focuses on visual cues that are used to prevent visual search. As stated earlier, understanding will only commence when the learners connects the verbal and pictorial information. With high visual search, learners unnecessarily use cognitive capacity for relating both information sources. Some studies report that visual cues fail in multimedia (Tabbers, Martens, \& van Merriënboer, 2004), whereas others show that cueing can be effective when the amount of necessary visual search, such as in complex animations, is high (Jeung, Chandler, \& Sweller, 1997). Mautone and Mayer (2001, Experiment 3) investigated the effect of signaling in a narrated animation and found that signaling was effective when both the animation and the narration were signaled (signaled words were spoken with a slower, deeper intonation), but not when neither the animation nor the narration was signaled. In another study, Craig, Gholson, and Driscoll (2002) failed to prove the effectiveness of a pedagogical agent with a signaling function. Possibly, the way that cueing was implemented in this study, namely, as rather global gestures in the direction of the location of the screen where the learner had to attend to, was not directive enough to serve the purpose of cueing and yield the desired effects.

In order to focus the attention to the parts in the 'pin code' animated model that visualize that this is a drawing with replacement, the pedagogical agent may first move to the ATM display and point to the position for the second number of the pin code on the display and then point to the highlighted figures from which the second number can be chosen. 
Typically, learners view animated models passively. With respect to modeling, Bandura (1976) observed a stronger effect when learners engage in active coding. Other researchers as well have advocated active learning (Chi et al., 1989; Mayer, 2001; Wittrock, 1974). The generation of self-explanations has proven to be a successful approach in order to engage in active processing of learning material (Chi et al., 1989; Renkl, 1997; Renkl \& Atkinson, 2002; Roy \& Chi, 2005). By generating self-explanations learners integrate newly learned information with prior knowledge, which yields a more integrated knowledge base with increased accessibility, better recall, and higher transfer of learning (Chi, de Leeuw, Chiu, \& LaVancher, 1994). Moreover, self-explaining forces learners to explicate their understanding and might help them to find out what they do and do not understand (Renkl \& Atkinson, 2002). The assumption is that active processing will yield germane cognitive load. The following guidelines allow learners to engage in self-explanations when learning from animated models.

First, there is a broad group of guidelines that can be summarized as expectancydriven instructional methods which enable learners to process instructional material more actively by predicting the next step in a process (Renkl, 1997). The focus of these guidelines is to help learners to construct or refine an initial schema. Hegarty et al. (2003) reported that learners who were prompted by questions to predict how a device worked before the animation continued, comprehended the working of the device better than learners who received no prompts. Also Mayer et al. (2003, Experiment 3) gave learners a question before showing an animation about the working of an electric motor and told them that they had to answer the question after the instruction. Learners who received pre-questions scored better on transfer than learners who did not receive pre-questions. Furthermore, Renkl (1997) found learners successful in solving problems in the domain of probability calculation when they 
engaged in anticipative reasoning. In anticipative reasoning learners first think about the next step in a task, for example in the solution process of a problem, and compare their understanding with the feedback provided by the learning environment before proceeding with the next step. To conclude, in a study in the field of biology, Moreno et al. (2001, Experiment 3) had learners design a plant, that is, determine the characteristics of leaves, root etc. and relate these to environmental features, such as rainfall. Learners who participated in the design of a plant before they listened to a spoken instruction, scored better on the more difficult transfer problems than learners who only had to listen to the spoken instruction.

In the 'pin code' animated model, the learner can be prompted to answer the question 'Is this a problem with or without replacement?' just before this question is discussed in the animated model. A textbox may appear to fill out the answer. Only after providing an answer the 'pin code' animated model will continue and explain that this is a drawing without replacement.

In conclusion, these studies indicate that inciting learners to actively anticipate the problem solving process (e.g., by a prequestion or having learners to predict the next step in a process) is an effective instructional method that enables learners to engage in relevant learning activities.

The second guideline, subgoaling, seems especially useful for novices who can easily be overwhelmed by a complete solution process as they do not know which elements in the process of solving a problem belong together. In subgoaling, learners are prompted to group coherent steps in a procedure into one meaningful subgoal. Subgoals can facilitate learners to solve novel problems by helping them to identify which parts of a previously learned solution procedure need to be modified in order to solve a novel problem (Catrambone, 1996, 1998). Cues, such as labels or visual markers, can support learners in creating subgoals and thus 
encourage a learner to self-explain the purpose of the steps. Take for example the situation in which a problem on gravity has to be solved. Without subgoals several steps might be presented that learners have to pass through in order to solve the problem. However, the learners are not encouraged to explain why some of these steps belong together. With subgoaling the first subgoal could be a bold face text in which the learners are asked to identify the forces that act on an object. It is likely that learners have to identify the 'forces that act on an object' in other gravity problems as well, but that the way to achieve this subgoal might be different. Subgoaling is closely related to segmentation. A segment indicates a coherent part within a process or event and in this respect functions as a cue that might enable learners to create a subgoal for that segment.

Imagine that the 'pin code' animated model is segmented. At the end of the segment in which it is concluded whether it is a drawing with or without replacement, learners can be prompted to formulate a subgoal by asking them: 'Which factor(s) in this problem determine whether it is a drawing with or without replacement?'. In this case the learner has two cues for formulating the subgoal: The question and the segmentation.

The third guideline, imagination, is derived from studies involving motor skills which have shown that imagining these skills before actually performing them leads to better results compared with not imagining these skills before performing them (Cooper, Tindall-Ford, Chandler, \& Sweller, 2001). Contrary to the expectancy-driven methods that focus on the acquisition of an initial schema, the major effect of imagination is the facilitation of schema automation (although imagination may facilitate schema construction). By imagination an existing schema can be rehearsed and further automated. As automated schemas can be performed without placing a load on working memory, imagination releases cognitive resources that can be used for other aspects of (learning) the task. Stimulating learners to 
imagine procedures and concepts can be an effective guideline for the more advanced or proficient learners, because imagination is only possible if a schema that can guide behavior has already been acquired. For example, learners who had to imagine the procedure to construct formulas in a spreadsheet outperformed learners who only had to study this procedure both in the number of correct solutions and the solution times (Cooper et al., 2001). Leahy and Sweller (2004) confirmed these findings in another domain (interpreting contour maps and graphs about weather) with school teachers and young children. Furthermore, they found an interaction between imagination and split-attention, that is, learners who had to imagine after reading a graph with integrated explanatory labels performed better than learners who had to read a graph with the explanatory labels on a separate page. Apparently, split-attention required so much cognitive resource that little capacity remained for performing the imagination technique.

More proficient learners first study the 'pin code' animated model. The animated model then disappears or the learners turn away from the screen. Subsequently, they are asked to imagine performing (and try to understand) the problem solving procedure shown before in the animated model.

The fourth guideline, using variability, focuses on the presentation of a sequence of tasks that differ in relevant features. The rationale behind the variability effect is that it encourages learners to identify and distinguish the relevant from the irrelevant features and by doing so develop appropriate schemas. For example, Quilici and Mayer (1996) exposed one group to a set of statistical word problems that varied in their structural features (e.g., the mathematical procedure that was needed to solve the problem), whereas another group was exposed to a set that varied only in surface features (e.g., the story line of the problem). On a transfer test, the group exposed to variability in structural features outperformed the group 
that was exposed to surface features. Variability is closely connected to contextual interference, that is, training conditions in which certain contextual factors prohibit a quick and smooth mastery of the skills being trained (van Merriënboer, Schuurman, de Croock, \& Paas, 2002). High contextual interference may be realized by presenting problems in a random order so that each successive problem requires learners to apply different knowledge and skills. This practice schedule enables them to compare the solutions of the problems and construct more general applicable schemas that can be used then in larger classes of problems. Although this might yield an increase in cognitive load and instruction time during the learning phase, it will generate higher transfer performance. For example, in the domain of computer numerically controlled machinery programming, Paas and van Merriënboer (1994) investigated the effects of problem format and variability. They compared a low- and a high-variability conventional condition in which conventional practice problems had to be solved with a low- and a high-variability worked example condition in which worked examples had to be studied. They found that learners who studied high variable worked examples scored better on transfer than learners who studied low variable worked examples. Moreover, they found that high variability was only effective (i.e., imposed germane cognitive load) in the worked-example condition, where the extraneous cognitive load was sufficiently low to allow learners to profit from increased variability. These findings have been confirmed in the domain of troubleshooting (de Croock, van Merriënboer, \& Paas, 1998; van Merriënboer et al., 2002).

An example of variability in the 'pin code' animated model is the introduction of another 'pin code' animated model, beside the original one, adapted in such a way that the pin code comprises 4 different numbers which makes it a drawing without replacement. This adaptation varies the animated model in a structural feature, because it changes the method 
that can be used to solve the problem. The original 'pin code' animated model can be solved by counting all possible combinations of four numbers with a particular formula (i.e., $10^{4}$ which results in 10,000 combinations). Eventually only one of these combinations is the correct one. In the adapted version the drawing is now without replacement and therefore another formula has to be calculated (i.e., the permutation formula).

To conclude, the variability guideline is an effective instructional method provided that the extraneous cognitive load is sufficiently low. Moreover, the variability guideline may take more cognitive load during training, but yield higher post-test performance.

To conclude this classification, Table 1 provides an overview of the design guidelines, their descriptions and examples.

\section{Insert Table 1 here}

It should be noted that there is a close relationship between the different sources of cognitive load and the complexity of the animated models. For simple animated models sufficient cognitive capacity is available for an increase of germane cognitive load. With animated models of intermediate complexity, germane cognitive load can only be increased when cognitive capacity is released by decreasing extraneous cognitive load. For highly complex animated models, both extraneous and intrinsic cognitive load should be decreased and, if possible, germane load increased.

\section{Factors Mediating the Effect of Design Guidelines}

Some caution should be taken when applying the guidelines. Several studies have revealed factors that mediate the instructional effects of the design guidelines. The first mediating factor is the prior knowledge of the learner. Recent research on cognitive load theory, for example, has proven that design guidelines that are beneficial for novice learners can be ineffective or even detrimental when applied to experts (Kalyuga, 2005; Kalyuga, 
Ayres, Chandler, \& Sweller, 2003). Novices typically lack the cognitive schemas that may release working memory resources and enable the learner to process information effectively. In the case of novices, the application of the design guidelines can compensate for this lack of schemas. More experienced learners, however, already possess schemas to process information effectively and the guidelines may yield instruction that is less effective for them. If the guidelines are nevertheless used by the designer of the instruction, more experienced learners will try connecting and integrating both schema information from their memory and the information based on the instruction. As this is redundant information that they cannot ignore, it can yield high cognitive load or even cognitive overload. This moderating effect of the level of expertise is referred to as the expertise reversal effect (Kalyuga et al., 2003). For more experienced learners the pretraining guideline would be less effective as they already possess the necessary schemas and are not confronted with a heavy intrinsic cognitive load. With respect to the imagination guideline it is clear that this guideline is not appropriate for novice learners, as they do not have the necessary schemas (Cooper et al., 2001).

A second mediating factor is the spatial ability of learners. For example, Mayer and Sims (1994) observed that high spatial ability learners profited more from animations with concurrent narration than low spatial ability learners. They concluded that the latter had to devote so much cognitive resources in constructing a mental visual representation that little resources remained for making connections between the visual and verbal representations. The high spatial ability learners, on the contrary, were able to build a visual representation with much less mental effort and therefore could devote more cognitive resources to the connection of visual and verbal representations.

A third mediating factor comprises the motivational aspects of learners. According to Fisher and Ford (1998), the allocation of effort toward learning activities is driven by 
individual motivational processes, such as personal goals and interests, incentives, individual personality differences, and metacognitive knowledge. In this respect, the pattern of cognitive load, that is, the specification of what is extraneous cognitive load and what is germane cognitive load, is not only a matter of instructional design but is mediated by the learners' learning activities which in turn depend on the personal goals and interests of the learner (Gerjets \& Scheiter, 2003). For example, evidence for the mediating role of motivation was provided by Holladay and Quinones (2003) who found that self-efficacy generality, that is, efficacy beliefs related to a specific task can be generalized to similar tasks, can be regarded as a mechanism to explain the relation between task variability and transfer performance. In a computer naval air defense simulation, the higher scores on far transfer could not be ascribed to the high variability tasks that learners engaged in, but to the higher self efficacy generality resulting from the high task variability. In other words, there was no direct relation between practice variability and far transfer when the effects of self-efficacy generality were taken away.

The last mediating factor to be discussed is age. One of the central findings in cognitive aging research is that the efficiency of working memory deteriorates with aging. Several explanations have been proposed to account for this decline (Paas, van Gerven, \& Tabbers, 2005). To start with, the reduced working memory view suggests that elder people have reduced processing capacity that becomes particular relevant with complex cognitive tasks (Gilinsky \& Judd, 1994; Salthouse, Mitchell, Skovronek, \& Babcock, 1989). When tasks become more complex older adults tend to be slower than younger adults. A second view, the reduced processing speed view, argues that reduced processing speed is a central mechanism in the explanation of age differences in performance (Fisk \& Warr, 1996; Salthouse, 1996). A third view contends that older people cannot suppress irrelevant or 
extraneous information to the same extent as do younger adults. According to this reduced inhibition view the extraneous information imposes more load on the cognitive system of older adults than that of younger adults. Finally, several studies report that older adults show reduced coordination and integration of information sources. In deductive reasoning, for example, Light, Zelinski, and Moore (1982) observed that older adults had difficulty in integrating information across several premises, although they could recognize the separate premises perfectly. Because the total cognitive capacity of older adults is smaller than that of younger adults, the application of guidelines based on cognitive load theory and presented in this review might be proportionally more effective. Paas, Camp, and Rikers (2001), investigated the effects of goal specifity on younger and elder learners. When they have to solve a problem with a specific goal novices typically rely on weak problem solving methods, such as working backward from the end goal (i.e., the problem solution) to sub goals, which imposes such a high level of extraneous cognitive load that little cognitive capacity remains for learning. When solving a problem without such a specific goal they cannot use weak problem solving methods and exert the cognitive capacity for learning. Paas et al. (2001) found that the absence of a specific goal had a larger beneficial effect on learning to solving maze problems for elderly learners than for younger learners. With respect to multimedia learning and age only little research has been conducted (for an overview see Paas et al., 2005). A study by van Gerven, Paas, van Merriënboer, Hendriks, and Schmidt (2003) revealed no proportional greater modality effect with older adults, although elder learners reported less cognitive load and needed less training time than younger learners when they studied multimodal materials (visuals and spoken text) rather than unimodal materials (visuals and written text). 
In the previous sections it has been argued that recent developments in information technology have enabled the application of animations and pedagogical agents with respect to cognitive modeling. Cognitive modeling deals with cognitive processes that are not directly observable. In order to make this possible, the cognitive processes of the model have to be externalized. As animations are transient they fit the dynamic nature of modeling. Moreover, animations can facilitate the externalization of the cognitive processes, especially when they are difficult to describe in words. Animated pedagogical agents can stimulate the learner to invest more effort to understand the model performance depicted in the animation and give specific support to the learner. It was also argued that the application of animations could pose substantial extraneous cognitive load on the learner's cognitive resources because information is dispersed both sequentially and simultaneously. According to the current focus of cognitive load theory, extraneous cognitive load should always be minimized; if this is insufficient to prevent cognitive overload, intrinsic cognitive load may be decreased as well, and at the same time, germane cognitive load is increased within the limits of totally available cognitive capacity. Therefore, three sets of guidelines were presented. First, guidelines were discussed that can decrease intrinsic cognitive load, such as the presentation of a range of tasks in a simple-to-complex sequence and pretraining. Second, guidelines were proposed that can decrease extraneous cognitive load, such as the implementation of pacing, segmentation, the modality effect, the contiguity effect, and signaling. Third, guidelines were discussed that stimulate germane cognitive load, such as the implementation of expectancydriven instructional methods, subgoaling, imagination, and variability.

It was also emphasized that the effectiveness of these guidelines depends on several mediating factors, such as, prior knowledge, spatial ability, motivation, and age of the learner. Figure 2 shows an integrative framework for the design of animated models based on 
a model by van Gerven et al. (2003). In the figure the guidelines are located near the type of cognitive load that they influence. The rectangle with 'Available cognitive capacity' is put in the center of the figure to indicate that optimizing animated models implies that the cognitive capacity has to be increased. In order to increase the available cognitive capacity, designers may decrease extraneous cognitive load (e.g., by using the contiguity guideline) and, if necessary, decrease intrinsic cognitive load (e.g., by using the sequence of simple-to-complex whole tasks). However, the available cognitive capacity, can be increased or decreased (depicted by the +/- symbol) by moderating factors, such as, spatial ability. For example, learners with high spatial ability may have more cognitive capacity available when learning from animated models than learners with low spatial ability, because they need less cognitive resources to construct a visual representation. The 'Available cognitive capacity' and 'Germane cognitive load' rectangles are overlapping to indicate that sufficient cognitive capacity is only a requisite for germane cognitive load. It does not guarantee that learners will engage in relevant learning activities that impose germane cognitive load. In most cases they will have to be incited to do so by applying design guidelines, such as expectancy driven methods. Furthermore, Figure 2 makes clear that an increase in germane cognitive load will increase performance in measures such as transfer and retention.

\section{Insert Figure 2}

This review summarized and evaluated guidelines that can be useful for animated models, that is, the use of animations in conjunction with a supportive pedagogical agent in modeling problem-solving processes. However, as stated in this review, animations are not always more effective than static visualizations. It is also clear that the creation of animations 
can be labor-intensive and expensive. Therefore, instructional designers should carefully consider whether animated models or static visualizations are most appropriate for the skills and knowledge that have to be learned.

The review also gave rise to some issues that justify a systematic research on animated models and the most appropriate guidelines to be used. First, researchers have focused on different kinds of domains. Most research is conducted with cause-and-effect systems, such as the origin of lightning (Mayer \& Chandler, 2001) and the working of devices (Hegarty et al., 2003). But researchers also studied the modeling of procedural tasks, such as performing a first-aid task (Michas \& Berry, 2000) and tying nautical knots (Schwan \& Riempp, 2004). Cause-and-effect systems involve knowledge about its components and knowledge about the behavior of these components. The two-phase approach which is put forward as a method to decrease intrinsic cognitive load is appropriate in this case, but less for sequentially oriented events with a strong procedural orientation, such as performing a first-aid task. In the latter case a simple-to-complex whole-task sequencing approach seems more appropriate.

Second, this review has shown that the design guidelines might interact, such as the interaction between modality and pacing (Tabbers et al., 2002), problem format and variability (Paas \& van Merriënboer, 1994) or imagination and spatial contiguity (Leahy \& Sweller, 2004). This indicates that the design guidelines can be further qualified when these interactions are taken into account.

Third, combinations of guidelines, such as the signaling and modality guideline, might be particular effective. The pedagogical agent in an animated model might be used to cue the learners' attention to the relevant part in the animation and meanwhile provide auditory explanatory information. 
Fourth, no research has been conducted on the relationships between the guidelines in large training programs. Especially for complex domains, such as learning to maintain computers, training programs are relevant. An interesting avenue for future research is to investigate whether the effect of guidelines in animated models in the context of such training programs is different from applying the guideline to a single animated model. In a training program for computer maintenance, for example, both a sequence of simple-to-complex whole tasks and segmentation can be applied. For computer maintenance, the simplest task might deal with only one obvious computer problem that has to be solved, whereas in the most complex task several interrelated problems might occur. In the training program each task might be first presented with an animated model, showing an expert explaining how a problem is solved followed by a similar task that learners have to perform themselves with a real computer. Whereas a sequence of simple-to-complex whole tasks is used to decrease intrinsic cognitive load, the segmentation guideline for decreasing extraneous cognitive load can be applied for the separate animated models. It would be interesting to know whether segmentation in animated models that are part of a training program will yield different effects compared with segmentation applied to isolated animated models.

In order to design instructionally effective animated models and to develop a comprehensive design theory for learning from animated models, a thorough and systematic research program is required. In particular this research program should investigate under which conditions particular animated models may be effective or not, that is, it should not only consider the guidelines and the mediating factors, but it should also take into account the four issues mentioned above. For example, this review proposed to apply the modality principle (i.e., use spoken explanations instead of written explanations) in order to decrease extraneous cognitive load. On the other hand, learner pacing seems to reverse the advantage 
of spoken over written explanations. In this case the research program has to formulate clear research questions that unravel under which conditions the modality principle is effective in animated models and under which conditions it is not. The application of animated models meets two focal points of contemporary educational theory. First, animated models performing and showing how they deal with real-life problems can enable the implementation of authentic learning in a meaningful context. Second, the modeling of cognitive processes with animated models is in line with the current focus on lifelong learning and problemsolving skills. From this perspective, animated models can be a promising instructional approach, provided that a balanced set of guidelines, based on the aforementioned comprehensive design theory, is applied in order to assure an optimal use of cognitive resources. 


\section{References}

Ainsworth, S., \& VanLabeke, N. (2004). Multiple forms of dynamic representations. Learning and Instruction, 14, 241-256.

Atkinson, R. K. (2002). Optimizing learning from examples using animated pedagogical agents. Journal of Educational Psychology, 94, 416-427.

Baddeley, A. (1997). Human memory: Theory and practice. East Sussex, UK: Psychology Press.

Bandura, A. (1976). Social learning theory. Englewood Cliffs, NJ: Prentice Hall.

Casey, C. (1996). Incorporating cognitive apprenticeship in multi-media. Educational Technology, Research and Development, 44, 74-84.

Catrambone, R. (1996). Generalizing solution procedures learned from examples. Journal of Experimental Psychology: Learning, Memory, and Cognition, 22, 1020-1031.

Catrambone, R. (1998). The subgoal learning model: Creating better examples so that learners can solve novel problems. Journal of Experimental Psychology: Applied, $127,355-376$.

Chandler, P., \& Sweller, J. (1994). Why some material is difficult to learn. Cognition and Instruction, 12, 185-233.

Chandler, P., \& Sweller, J., (1996).Cognitive load while learning to use a computer program. Applied Cognitive Psychology, 10, 151-170.

Chee, Y. C. (1995). Cognitive apprenticeship and its application to the teaching of Smalltalk in a multimedia interactive learning environment. Instructional Science, 23, 133-161.

Chi, M. T. H., Bassok, M., Lewis, M. W., Reimann, P., \& Glaser, R. (1989). Selfexplanations: How learners study and use examples in learning to solve problems. Cognitive Science, 13, 145-182. 
Chi, M. T. H., de Leeuw, N., Chiu, M., \& LaVancher, C. (1994). Eliciting self-explanations improves understanding, Cognitive Science, 18, 439-477.

Clarebout, G., Elen, J., Johnson, W. L., \& Shaw, E. (2002). Animated pedagogical agents: An opportunity to be grasped? Journal of Educational Multimedia and Hypermedia, $11,267-286$.

Clark, R. E., \& Choi, S. (2005). Five design principles for experiments on the effects of animated pedagogical agents. Journal of Educational Computing Research, 32, 209225.

Clark, J. M., \& Paivio, A. (1991). Dual coding theory and education. Educational Psychology Review, 3, 149-210.

Collins, A. (1991). Cognitive apprenticeship and instructional technology. In L. Idol \& B. F. Jones (Eds.), Educational values and cognitive instruction: Implications for reform (pp. 121-138). Hillsdale, NJ: Lawrence Erlbaum.

Collins, A., Brown, J. S., \& Newman, S. E. (1989). Cognitive apprenticeship: Teaching the crafts of reading, writing, and mathematics. In L. B. Resnick (Ed.), Knowing, learning, and instruction: Essays in honor of Robert Glaser (pp. 453-494). Hillsdale, NJ: Lawrence Erlbaum.

Cooper, G., Tindall-Ford, S., Chandler, P., \& Sweller, J. (2001). Learning by imagining. Journal of Experimental Psychology: Applied, 7, 68-82.

Cox, R., McKendree, J., Tobin, R., Lee, J., \& Mayes, T. (1999). Vicarious learning from dialogue and discourse. Instructional Science, 27, 431-458.

Craig, S. D., Gholson, B., \& Driscoll, D. M. (2002). Animated pedagogical agents in multimedia educational environments: Effect of agent properties, picture features, and redundancy. Journal of Educational Psychology, 94, 428-434. 
Craig, S. D., Graesser, A. C., Sullins, J., \& Gholson, B. (2004). Affect and learning: An exploratory look into the role of affect in learning with AutoTutor. Journal of Educational Media, 29, 241-250.

de Croock, M., van Merriënboer, J. J. G., \& Paas, F. (1998). High versus low contextual interference in simulation-based training of troubleshooting skills: Effects on transfer performance and invested mental effort. Computers in Human Behavior, 14, 249-267.

Dehn, D. M., \& van Mulken, S. (2000). The impact of animated interface agents: A review of empirical research. International Journal of Human-Computer Studies, 52, 1-22.

Fisher, F.L., \& Ford, J. K. (1998). Differential effects of learner effort and goal orientation on two learning outcomes. Personnel Psychology, 51, 397-420.

Fisk, J. E., \& Warr, P. (1996). Age and working memory: The role of perceptual speed, the central executive, and the phonological loop. Psychology and Aging, 11, 316-323.

Gerjets, P., \& Scheiter, K. (2003). Goal configurations and processing strategies as moderators between instructional design and cognitive load: Evidence from hypertextbased instruction. Educational Psychologist, 38, 33-41.

Gilinsky, A. S., \& Judd, B. B. (1994). Working memory and bias in reasoning across the life span. Psychology and Aging, 9, 356-371.

Ginns, P. (2005). Meta-analysis of the modality effect. Learning and Instruction, 15, 313331.

Hegarty, M. (2004). Dynamic visualizations and learning: Getting to the difficult questions. Learning and Instruction, 14, 343-352.

Hegarty, M., Kriz, S., \& Cate, C. (2003). The roles of mental animations and external animations in understanding mechanical systems. Cognition and Instruction, 21, 325360. 
Holladay, C. L., \& Quinones, M. A. (2003). Practice variability and transfer of training: The role of self-efficacy generality. Journal of Applied Psychology, 88, 1094-1103.

Jeung, H., Chandler, P., \& Sweller, J. (1997). The role of visual indicators in dual sensory mode instruction. Educational Psychology, 17, 329-343.

Jonassen, D. (1999) Designing constructivist learning environments. In C.M. Reigeluth (Ed.), Instructional design theories and models: A new paradigm of instructional theory (Vol. II) (pp. 215-239). Mahwah, NJ: Lawrence Erlbaum Associates.

Kalyuga, S. (2005). Prior knowledge principle in multimedia learning. In R. Mayer (Ed.), Cambridge handbook of multimedia learning (pp. 325-338). New York: Cambridge University Press.

Kalyuga, S., Ayres, P., Chandler, P., \& Sweller, J. (2003). The expertise reversal effect. Educational Psychologist, 38, 23-31.

Kalyuga, S., Chandler, P., \& Sweller, J. (1999). Managing split-attention and redundancy in multimedia instruction. Applied Cognitive Psychology, 13, 351-371.

Kitsantas, A., Zimmerman, B. J., \& Cleary, T. (2000). The role of observation and emulation in the develoment of athletic self-regulation. Journal of Educational Psychology, 91, $241-250$.

Koroghlanian, C., \& Klein, J. D. (2004). The effect of audio and animation in multimedia instruction. Journal of Educational Multimedia and Hypermedia, 13, 23-46.

Leahy, W., \& Sweller, J. (2004). Cognitive load and the imagination effect. Applied Cognitive Psychology, 18, 857-875.

Light, L. L., Zelinski, E. M., \& Moore, M. (1982). Adult age differences in reasoning from new information. Journal of Experimental Psychology: Learning, Memory, and Cognition, 8, 435-447. 
Lowe, R. K. (1999). Extracting information from an animation during complex visual learning. European Journal of Psychology of Education, 14, 225-244.

Lowe, R. K. (2003). Animation and learning: Selective processing of information in dynamic graphics. Learning and Instruction, 13, 157-176.

Mautone, P. D., \& Mayer, R. E. (2001). Signaling as a cognitive guide in multimedia learning. Journal of Educational Psychology, 93, 377-389.

Mayer, R. (2001). Multimedia learning. New York: Cambridge University Press.

Mayer, R. (2005a). Principles in managing essential processing in multimedia learning: Segmenting, pretraining, and modality principles. In R. Mayer (Ed.), Cambridge handbook of multimedia learning (pp. 169-182). New York: Cambridge University Press.

Mayer, R. (2005b). Principles for reducing extraneous processing in multimedia learning: Coherence, signaling, redundancy, spatial contiguity, and temporal contiguity principles. In R. Mayer (Ed.), Cambridge handbook of multimedia learning (pp. 183200). New York: Cambridge University Press.

Mayer, R. (2005c). Principles of multimedia learning based on social cues: Personalization, voice, and image principles. In R. Mayer (Ed.), Cambridge handbook of multimedia learning (pp. 201-214). New York: Cambridge University Press.

Mayer, R. E., \& Chandler, P. (2001). When learning is just a click away: Does simple user interaction foster deeper understanding of multimedia messages? Journal of Educational Psychology, 93, 390-397.

Mayer, R. E., Dow, G. T., \& Mayer, S. (2003). Multimedia learning in an interactive selfexplaining environment: What works in the design of agent-based microworlds. Journal of Educational Psychology, 95, 806-812. 
Mayer, R. E., Mathias, A., \& Wetzell, K. (2002). Fostering understanding of multimedia messages through pre-training: Evidence for a two-stage theory of mental model construction. Journal of Experimental Psychology: Applied, 8, 147-154.

Mayer, R. E., \& Moreno, R. (1998). A split-attention effect in multimedia learning: Evidence for dual processing systems in working memory. Journal of Educational Psychology, $90,312-320$.

Mayer, R. E., \& Moreno, R., (2002). Animation as an aid to multimedia learning. Educational Psychology Review, 14, 87-99.

Mayer, R. E., \& Moreno, R. (2003). Nine ways to reduce cognitive load in multimedia learning. Educational Psychologist, 38, 43-53.

Mayer, R. E., \& Moreno, R., Boire, M., \& Vagge, S. (1999). Maximizing constructivist learning from multimedia communications by minimizing cognitive load. Journal of Educational Psychology, 91, 638-643.

Mayer, R. E., \& Sims, V. K. (1994). For whom is a picture worth a thousand words? extensions of a dual-coding theory of multimedia learning. Journal of Educational Psychology, 86, 389-401.

Mayer, R. E., Sobko, K., \& Mautone, P. D. (2003). Social cues in multimedia learning: Role of speaker's voice. Journal of Educational Psychology, 95, 419-425.

Meichenbaum, D. (1977). Cognitive behavior modification: An integrative approach. New York: Plenum.

Michas, I. C., \& Berry, D. C. (2000). Learning a procedural task: Effectiveness of multimedia presentations. Applied Cognitive Psychology, 14, 555-575.

Moundridou, M., \& Virvou, M. (2002). Evaluating the persona effect of an interface agent in a tutoring system. Journal of Computer Assisted Learning, 18, 253-261. 
Moreno, R. (2005). Multimedia learning with animated pedagogical agents. In R. Mayer (Ed.), Cambridge handbook of multimedia learning (pp. 507-524). New York: Cambridge University Press.

Moreno, R., \& Mayer, R. E. (1999). Cognitive principles of multimedia learning: The role of modality and contiguity. Journal of Educational Psychology, 91, 358-368.

Moreno, R., Mayer, R. E., Spires, E., \& Hiller, A. (2001). The case for social agency in computer-based teaching: Do learners learn more deeply when they interact with animated pedagogical agents? Cognition and Instruction, 19, 177-213.

Moreno, R., \& Valdez, A. (2005). Cognitive load and learning effects of having students organize pictures and words in multimedia environments: The role of student interactivity and feedback. Educational Technology, Research and Development, 53, $35-45$.

Mousavi, S. Y., Low, R., \& Sweller, J. (1995). Reducing cognitive load by mixing auditory and visual presentation modes. Journal of Educational Psychology, 87, 319-334.

Paas, F., Camp, G., \& Rikers, R. (2001). Instructional compensation for age-related cognitive declines: Effects of goal specificity in maze learning. Journal of Educational Psychology, 93, 181-186.

Paas, F. Renkl, A., \& Sweller, J. (2003). Cognitive load theory and instructional design: Recent developments. Educational Psychologist, 38, 1-4.

Paas, F., Renkl, A., \& Sweller, J. (2004). Cognitive load theory: Instructional implications of the interaction between information structures and cognitive architecture. Instructional Science, 32, 1-8. 
Paas, F., Van Gerven, P. W. M., \& Tabbers, H. K. (2005). The cognitive aging principle in multimedia learning. In R. Mayer (Ed.), Cambridge handbook of multimedia learning (pp. 339-354). New York: Cambridge University Press.

Paas, F., \& van Merriënboer, J. J. G. (1994). Variability of worked examples and transfer of geometrical problem solving skills: A cognitive load approach. Journal of Educational Psychology, 86, 122-133.

Paivio, A. (1986). Mental representations: A dual coding approach. Oxford, England: Oxford University Press.

Park, O-C., \& Hopkins, R. (1993). Instructional conditions for using dynamic visual displays. Instructional Science, 21, 427-449.

Penney, C. (1989). Modality effects and the structure of short-term verbal memory. Memory and Cognition, 17, 398-422.

Pollock, E., Chandler, P., \& Sweller, J. (2002). Assimilating complex information. Learning and Instruction, 12, 61-86.

Reeves, B., \& Nass, C. (1996). The media equation: How people treat computers, television, and new media like real people and places. New York: Cambridge University Press.

Renkl, A. (1997). Learning from worked-out examples: A study on individual differences. Cognitive Science, 21, 1-29.

Renkl, A., \& Atkinson, R. K. (2002). Learning from examples: Fostering self-explanations in computer-based learning environments. Interactive Learning Environments, 10, 105119.

Rieber, L. P. (1990). Animation in computer-based instruction. Educational Technology, Research and Development, 38, 77-86. 
Rieber, L. P., \& Kini, A. S. (1991). Theoretical foundations of instructional applications of computer-generated animated visuals. American Journal of Psychology, 18, 83-88.

Roy, M., \& Chi, M., T., H., (2005). The self-explanation principle in multimedia learning. In R. Mayer (Ed.), Cambridge handbook of multimedia learning (pp. 271-286). New York: Cambridge University Press.

Salthouse, T. A. (1996). The processing-speed theory of adult age differences in cognition. Psychological Review, 103, 403-428.

Salthouse. T. A., Mitchell, D. R. D., Skovronek, E., \& Babcock, R. L. (1989). Effects of adult age and working memory on reasoning and spatial abilities. Journal of Experimental Psychology: Learning, Memory, and Cognition, 15, 507-516.

Schnotz, W. (2002). Towards an integrated view of learning from text and visual displays. Educational Psychology Review, 14, 101-120.

Schwan, S., \& Garsoffky, B. (2004). The cognitive representation of filmic event summaries. Applied Cognitive Psychology, 18, 37-55.

Schwan, S., \& Riempp, R. (2004). The cognitive benefits of interactive videos: Learning to tie nautical knots. Learning and Instruction, 14, 293-305.

Schwan, S., Garsoffky, B., \& Hesse, F. W. (2000). Do film cuts facilitate the perceptual and cognitive organization of activity sequences? Memory and Cognition, 28, 214-223.

Shah, P., \& Freedman, E. G. (2003). Visuospatial cognition in electronic learning. Journal of Research on Computing in Education, 29, 315-324.

Sweller, J. (1988). Cognitive load during problem solving: Effects on learning. Cognitive Science, 12, 257-285.

Sweller, J. (1999). Instructional design in technical areas. Melbourne: ACER. 
Sweller, J. (2004). Instructional design consequences of an analogy between evolution by natural selection and human cognitive architecture. Instructional Science, 32, 9-31.

Sweller, J. (2005). The redundancy principle in multimedia learning. In R. Mayer (Ed.), Cambridge handbook of multimedia learning (pp. 159-168). New York: Cambridge University Press.

Sweller, J. (2006). The worked example effect and the human cognitive architecture. Learning and Instruction, 16, 165-169).

Sweller, J., van Merriënboer, J. J. G., \& Paas, F. (1998). Cognitive architecture and instructional design. Educational Psychology Review, 10, 251-296.

Tabbers, H. (2002). The modality of text in multimedia instruction: Refining the design guidelines Unpublished doctoral dissertation. Heerlen, The Netherlands: Open University of the Netherlands.

Tabbers, H., Martens, R., \& van Merriënboer, J. J. G. (2004). Multimedia instructions and cognitive load theory: Effects of modality and cueing. British Journal of Educational Psychology, 74, 71-81.

Tarmizi, R. A., \& Sweller, J. (1988). Guidance during mathematical problem solving. Journal of Educational Psychology, 80, 424-436.

Tversky, B., Morrison, J. B., \& Betrancourt, M. (2002). Animation: Does it facilitate learning? International Journal of Human-Computer Studies, 57, 247-262.

Quilici, J. L., \& Mayer, R. E. (1996). Role of examples in how students learn to categorize statistics word problems. Journal of Educational Psychology, 88, 144-161.

Van Gerven, P., Paas, F., van Merriënboer, J., Hendriks, M., \& Schmidt, H. (2003). The efficiency of multimedia learning into old age. British Journal of Educational Psychology, 73, 489-505. 
Van Gog, T., Paas, F., \& van Merriënboer, J. J. G. (2004). Process-oriented worked examples: Improving transfer performance through enhanced understanding. Instructional Science, 32, 83-98.

Van Merriënboer, J. J. G., Kirschner, P. A., \& Kester, L. (2003). Taking the load off a learner's mind: Instructional design for complex learning. Educational Psychologist, $38,5-13$.

Van Merriënboer, J. J. G., Schuurman, J., de Croock, M., \& Paas, F. (2002). Redirecting learners' attention during training: Effects on cognitive load, transfer test performance and training efficiency. Learning and Instruction, 12, 11-37.

Van Merriënboer, J. J. G. (1997). Training complex cognitive skills. Englewood Cliffs, NJ:Educational Technology Publications.

Van Merriënboer, J. J. G., \& Sweller, J. (2005). Cognitive load theory and complex learning: Recent developments and future directions. Educational Psychology Review, 17, 147177.

Weiss, R. E., Knowlton, D. S., \& Morrison, G. R. (2002). Principles for using animation in computer-based instruction: Theoretical heuristics for effective design. Computers in Human Behavior, 18, 465-477.

Wetzel, D. C., Radtke, P. H., \& Stern, H. W. (1994). Instructional effectiveness of video media. Hillsdale/Mahwah, NJ: Lawrence Erlbaum.

Wittrock, M. C. (1974). Learning as a generative activity. Educational Psychologist, 11, 8795.

Zacks, J. M., \& Tversky, B. (2001). Event structure in perception and conception. Psychological Bulletin, 127, 3-21. 
Zimmerman, B. J., \& Kitsantas, A. (2002). Acquiring writing revision and self-regulatory skills through observation and emulation. Journal of Educational Psychology, 94, $660-668$. 
Table 1

Summary of Design Guidelines for Animated Models

\begin{tabular}{lll}
\hline Guideline & Description & Example \\
\hline $\begin{array}{ll}\text { Decrease intrinsic cognitive load } \\
\text { 1. sequence of simple-to-complex }\end{array}$ & $\begin{array}{l}\text { Present animated models that require the integration } \\
\text { of different skills and knowledge. Start with simple }\end{array}$ & $\begin{array}{l}\text { Make the animated model more complex by } \\
\text { chole tasks }\end{array}$ \\
& gradualing the probability that a pin code of 6 \\
& First present isolated components before the & First present definitions of terms, such as, drawing \\
2. Pretraining & interaction between these components is instructed & without replacement, order is relevant. Then present \\
& in the animated model & the animated model in which these terms interact
\end{tabular}

Decrease extraneous cognitive load

1. Pacing

Allow learners to adapt the tempo of presentation of Learners may pause, continue or move forward/ the animated model to their cognitive needs

backward in the animated model (e.g., with a slider bar) 


\begin{tabular}{|c|c|c|}
\hline Guideline & Description & Example \\
\hline 2. Segmentation & $\begin{array}{l}\text { Divide animated models in several segments in } \\
\text { which each segment corresponds with an important } \\
\text { part of a procedure or process }\end{array}$ & $\begin{array}{l}\text { Segment } 1 \text { determines whether it is a 'drawing with } \\
\text { replacement or not'; segment } 2 \text { determines whether } \\
\text { the 'order is relevant or not'; in segment } 3 \text { the } \\
\text { problem solving method is chosen, etc. }\end{array}$ \\
\hline 3. Modality principle & $\begin{array}{l}\text { Present textual explanations in animated models in } \\
\text { spoken format }\end{array}$ & Use spoken explanations \\
\hline 4. Contiguity principle & $\begin{array}{l}\text { Present textual explanations in animated models } \\
\text { contiguously in time or space }\end{array}$ & $\begin{array}{l}\text { When the pedagogical agent points to the } \\
\text { highlighted figures, the explanation that the second } \\
\text { number of the pin code can be chosen from these } \\
\text { figures must be spoken at the same time }\end{array}$ \\
\hline 5. Signaling or cueing & $\begin{array}{l}\text { Present cues to prevent visual search in animated } \\
\text { models }\end{array}$ & $\begin{array}{l}\text { The pedagogical agent first points to the ATM } \\
\text { display to the position of the second number of the } \\
\text { pincode and then point to the highlighted figures to } \\
\text { focus the attention to the part of the animated model } \\
\text { where it is visualized that this is a drawing with } \\
\text { replacement }\end{array}$ \\
\hline
\end{tabular}




\begin{tabular}{|c|c|c|}
\hline Guideline & Description & Example \\
\hline \multicolumn{3}{|l|}{ Increase germane cognitive load } \\
\hline 1. Expectancy-driven methods & $\begin{array}{l}\text { Present opportunities in animated models to predict } \\
\text { the next step in a process }\end{array}$ & $\begin{array}{l}\text { The learner is prompted to answer the question 'Is } \\
\text { this a drawing with or without replacement?'. After } \\
\text { answering the animated model continues }\end{array}$ \\
\hline 2. Subgoaling & $\begin{array}{l}\text { Prompt learners in animated models to group } \\
\text { coherent steps of a procedure into a meaningful } \\
\text { subgoal }\end{array}$ & $\begin{array}{l}\text { At the end of the segment in which it is concluded } \\
\text { whether it is a drawing with or without replacement, } \\
\text { the learner can be prompted to formulate a subgoal } \\
\text { by asking 'Which factor(s) determine in this } \\
\text { problem whether it is a drawing with or without } \\
\text { replacement?' }\end{array}$ \\
\hline 3. Imagination & $\begin{array}{l}\text { Stimulate learners to imagine procedures and } \\
\text { concepts that are used in animated models }\end{array}$ & $\begin{array}{l}\text { Learners first study the 'pin code' animated model } \\
\text { and then have to imagine performing the problem } \\
\text { solving procedure just shown }\end{array}$ \\
\hline
\end{tabular}




\begin{tabular}{lll}
\hline Guideline & Description & Example \\
\hline 4. Variability & Present problems that vary in relevant features & Adapt the animated model in such a way that each \\
& number of the pin code must be unique (which \\
& makes it a drawing without replacement). This has a \\
& consequence for the problem solving method \\
\hline
\end{tabular}

Note: In the column 'Example', the guidelines are applied to the 'pin code' animated model. In this animated model, a person has to guess the correct pin code of a cash card in one trial. A pedagogical agent in the animated model provides explanations. 


\section{Figure Caption}

Figure 1. Graphics from the 'pin code' animated model. Figure 1a shows a person standing before the ATM machine. Figure $1 \mathrm{~b}$ shows the same person ready to press the second number of the pin code. The ten figures from which the person can choose are highlighted. The pedagogical agent (the dolphin) guides the attention to that part.

Figure 2. An integrative framework for the design of animated models. Grey rectangles represent dependent variables. White rectangles with discontinuous arrows represent moderating factors. Continuous arrows represent causal relations. 


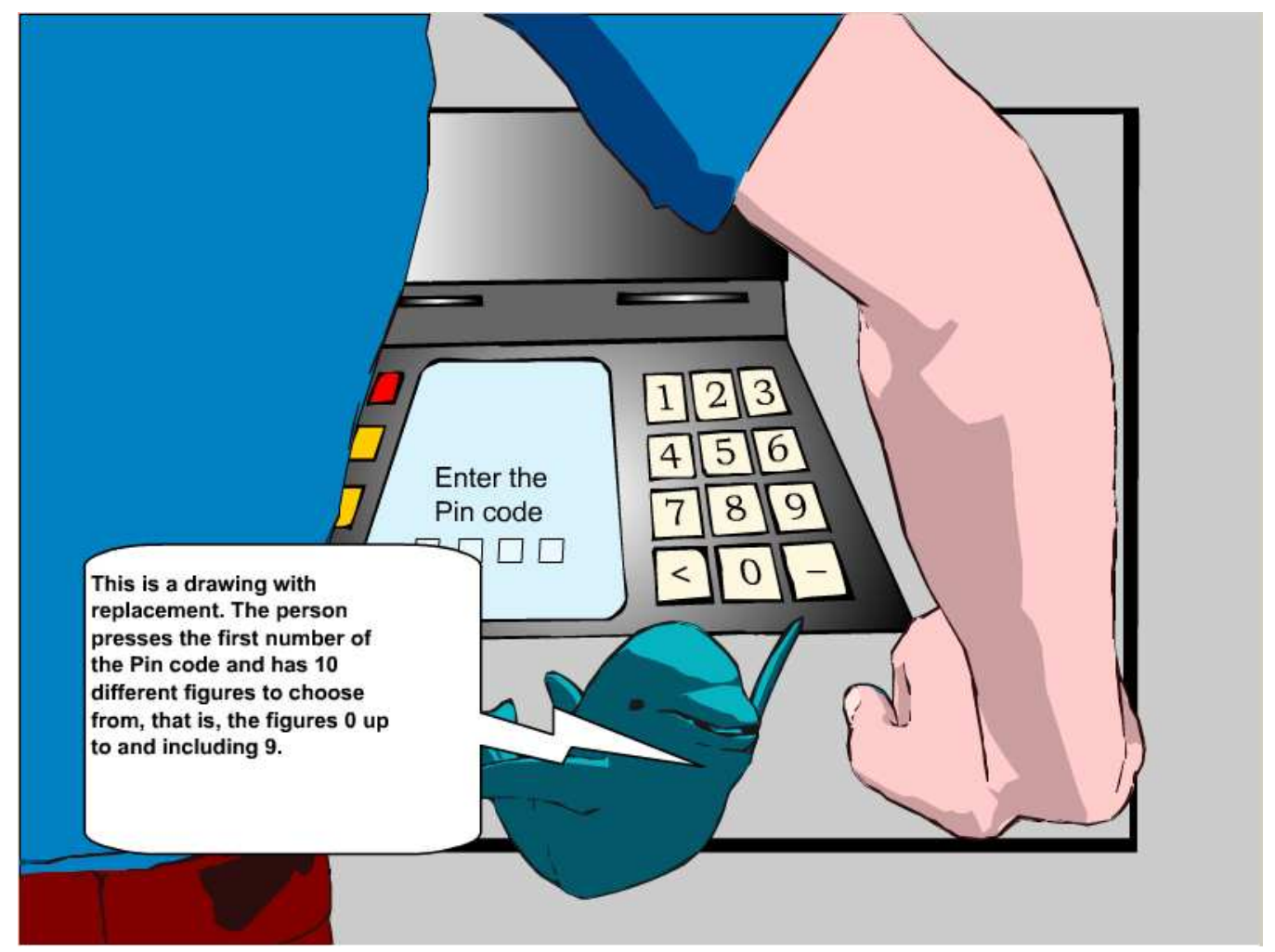

Figure 1a

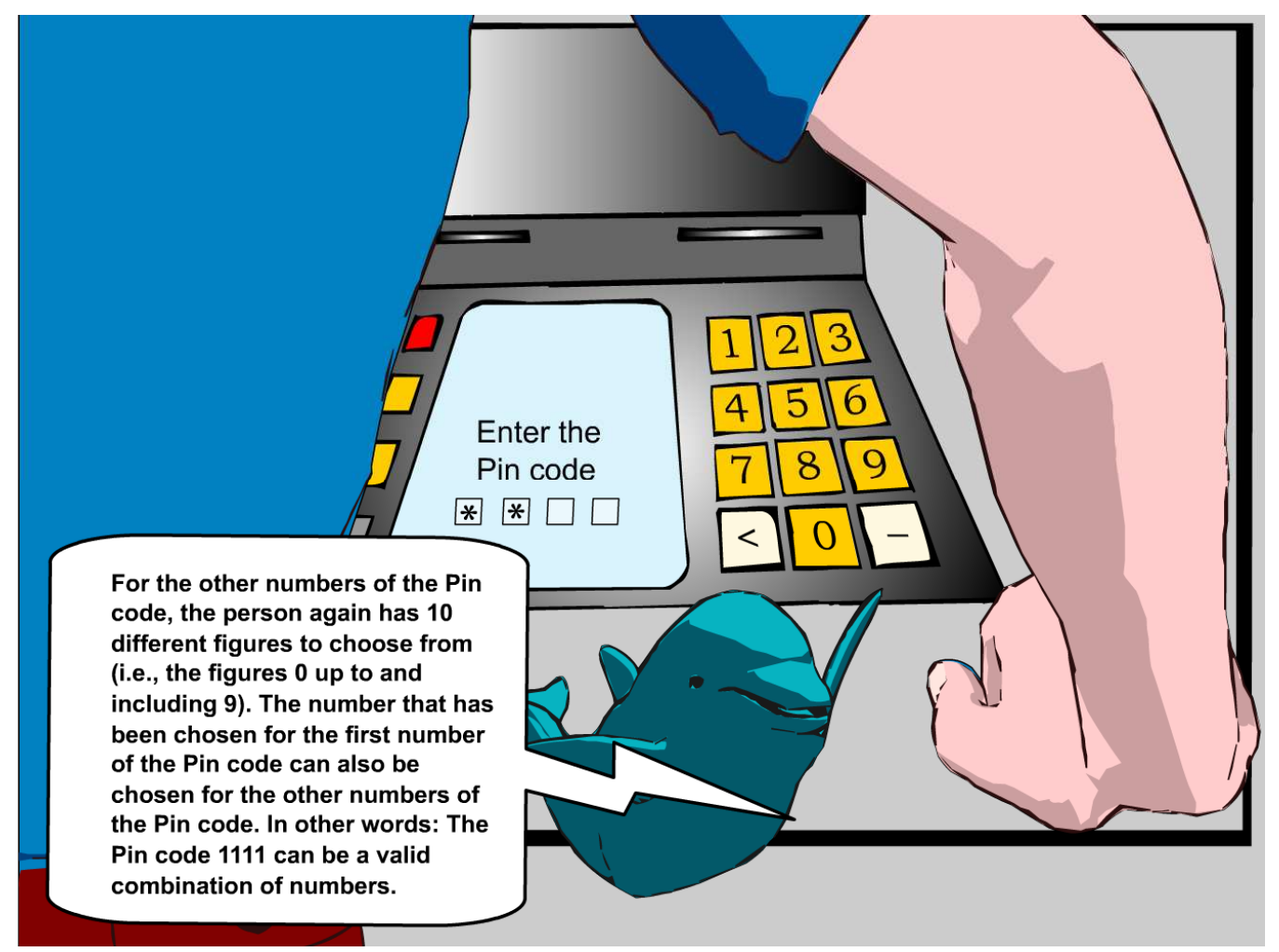

Figure 1b 


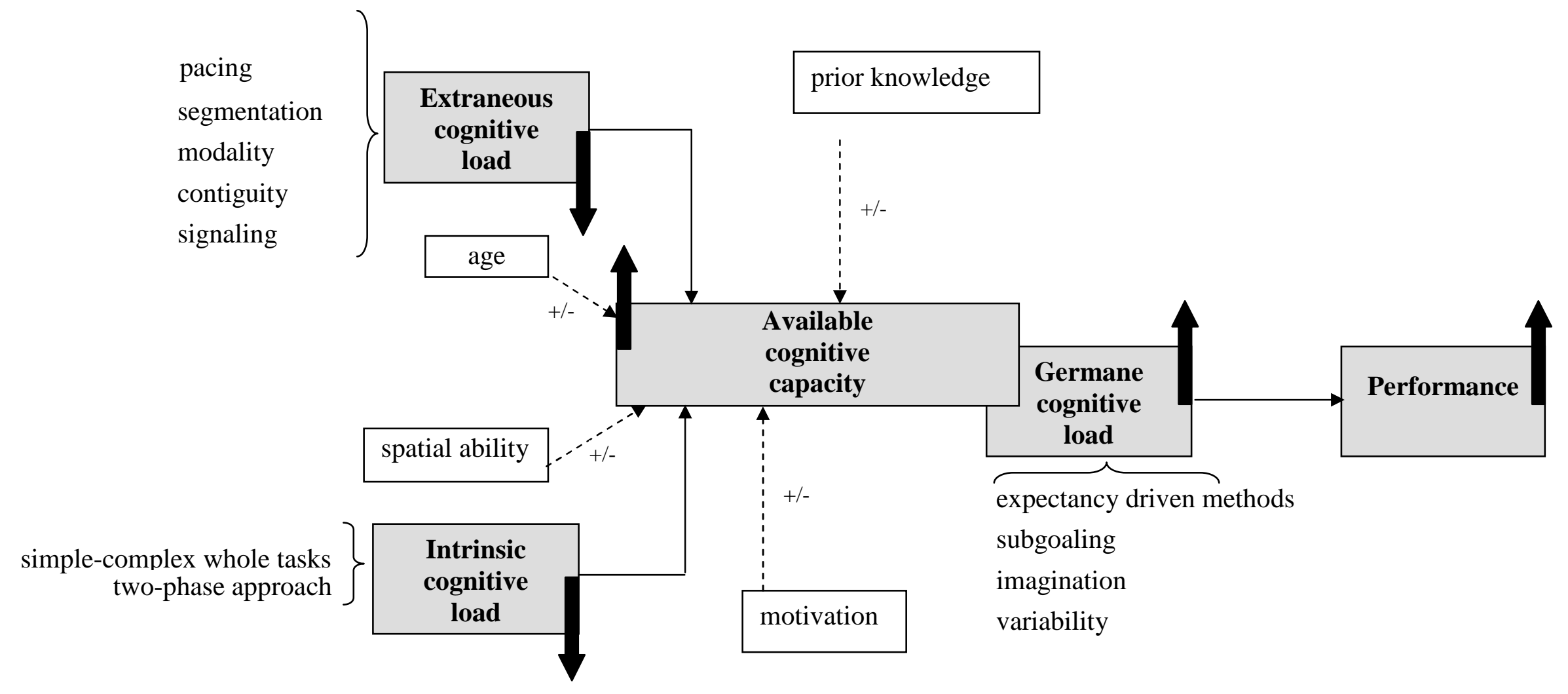

